\title{
Social Media Usage or Addiction: Social Media Addiction among Late Adolescence
}

\author{
Nazia Yaqoob*, Shumaila Mehnaz and Ammarah Saleem \\ Department of Applied Psychology, Government College Women University, Faisalabad, Pakistan
}

Email of corresponding author: naziayaqoob@gcwuf.edu.pk

\begin{abstract}
Current study aims to measure social media addiction (SMA) level difference across age, Facebook usage, and duration of social media (SM) usage among late adolescence. The sample of the present study comprises of 230 (74 men and 156 women). The mean age of the study sample was $19.68 \pm 1.11$ and they were selected from different academic institutions of Faisalabad by using convenience sampling technique. Descriptive statistics and Independent sample t-test was run for analysis. Results indicates that FB and Whatsapp are most widely used SM platforms, further male gender is more addicted to SM and as much there is an increase in duration of SM usage SMA also increases.
\end{abstract}

Keywords: Social Media Addiction; Social Media; Late Adolescence; Age; Pakistan.

\section{INTRODUCTION}

In current era use of social media (SM) increasing day by day with enhancement of gadgets. This easy access supporting many people to use SM most of the time. On one hand this situation is helping people to connect with all the world in no time but on the other hand causing social media addiction (SMA) in people. Use of social media is increasing day by day, and Facebook and WhatsApp are predominant in this group. Entertainment and friendship are a major purpose of using it. However, their use and effect in changing health behavior are still unclear (Prajapati et al., 2020). As more Americans have adopted SM, the SM user base has also grown more representative of the broader population. Young adults were among the earliest SM adopters and continue to use these sites at high levels ("Demographics of SM users and adoption in the United States," 2019).

After 15 years of operation, Facebook is still one of the most used SM platforms in the US. Facebook ranks second in platform usage after YouTube. According to latest figures $76 \%$ of 18 24 years old use Facebook, 75\% of 18-24 years old use Instagram, in terms of gender, $43 \%$ of women use Instagram while $31 \%$ of men use it, $44 \%$ of 18 24 years old use Twitter with more men than women plus 38 million Pakistanis were Facebook user in July 2020 ("Social Media demographics to inform your brand's strategy in 2020," 2020). From the beginning of 2019, with WhatsApp user numbers figured at 1.5 billion in last four years starting from late 2016. WhatsApp is one of the world's top apps. It has pulled ahead of Facebook Messenger, making it the biggest app in the world outside of the seemingly untouchable Facebook ("WhatsApp revenue and usage statistics (2020)," 2020). Current study aims to assess SMA level difference across age, Facebook usage or not, and duration of SM usage among late adolescence.

\section{METHOD}

The present study based on comparative group research design conducted in 2019 at Faisalabad Punjab, Pakistan. In this study SMA level compared across several group i.e. gender, Facebook user or not along with other SM, and duration of SM usage. SMA Scale developed by Al-Menayes (2015) was used to measure level of SMA. The sample of the present study comprises of 230 (74 men and 156 women). The mean age of the study sample was $19.68 \pm 1.11$ and they were selected from different academic institutions of Faisalabad by using convenience sampling technique. The inclusion criteria consist of at least one year of SM usage and age between 19 to 22 . SM include Facebook, WhatsApp, Tweeter, Instagram, and Google+ usage. Statistical Package for Social Sciences (SPSS) used for data analysis.

\section{RESULTS}

Findings of the current study are stated in tables below. Table 1 indicates the demographic 
characteristics of the study participants. Table 2 explains the comparison on study variables and SMA among late adolescence. Whereas Figure 1 declares types of SM used among late adolescence.

Analysis in Table 2 indicates that male and participants with more duration of SM usage have higher level of SMA as compared to female and participants with less duration of SM usage at $\mathrm{p}<0.01$. However, no significant difference exists between FB and non-FB users on SMA.
Table 1: Frequencies and Percentages of Sample Characteristics

\begin{tabular}{|cccc|}
\hline \multicolumn{2}{c}{ Variables } & $\boldsymbol{F}$ & Percentage \\
Gender & Male & 74 & 32.2 \\
& Female & 156 & 67.8 \\
& 19 & 176 & 54.8 \\
Age & 20 & 49 & 21.3 \\
& 21 & 20 & 8.7 \\
& 22 & 35 & 15.2 \\
Socio & Low & 20 & 8.7 \\
economic & Middle & 197 & 85.7 \\
Status & High & 13 & 5.7 \\
Duration of & 1-2 years & 122 & 53 \\
SM usage & 3-4 years & 108 & 47 \\
\hline
\end{tabular}

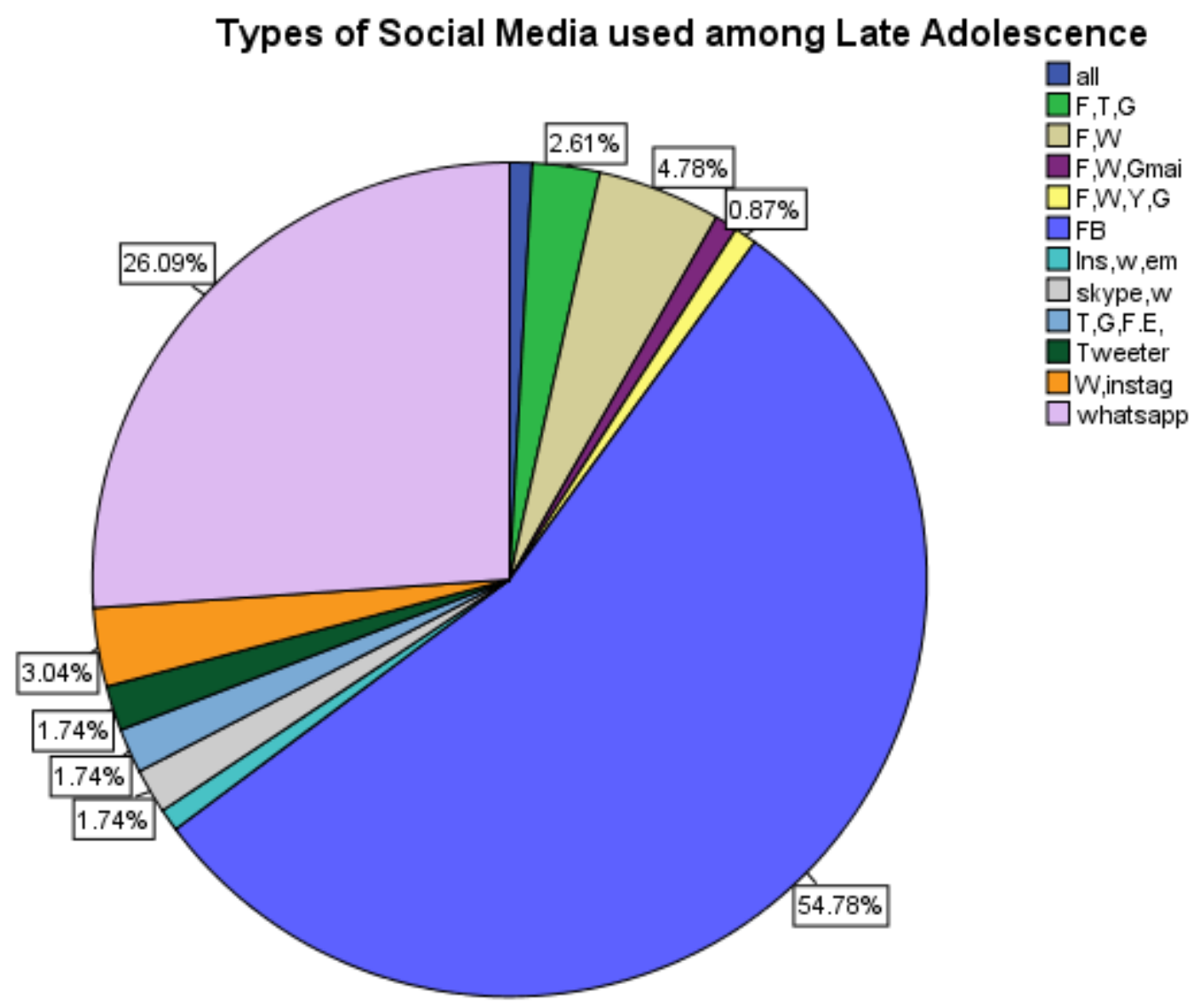

Figure 1: Describes FB as the most widely used SM among Late Adolescence with greatest proportion 54.78\% of total media usage (Tweeter, Google hangout, Facebook, Skype, Instagram, and Email/Gmail). Whatsapp is the second widely used SM among adolescence with proportion of $26.09 \%$ of total media usage categories. 
Table 2: Independent Sample T-Test for Difference on SMA Level Across FB and Non-FB User, Gender and Duration of SM Usage $\mathrm{N}=230$

\begin{tabular}{|ccccccc|}
\hline \multirow{2}{*}{ Variables } & & $\boldsymbol{N}$ & $\mathbf{M}(\mathbf{S D})$ & $\boldsymbol{t}$ & $\boldsymbol{p}$ & Cohen's $\boldsymbol{d}$ \\
& FB user & 118 & $38.84(8.41)$ & & & \\
\multirow{2}{*}{ FB User Category } & Non-FB user & 112 & $40.52(8.7)$ & 1.48 & .140 & 0.20 \\
& Male & 74 & $43.59(5.46)$ & & & \\
\multirow{2}{*}{ Gender } & Female & 156 & $37.79(9.20)$ & 5.02 & .001 & 0.77 \\
& 1-2 Years & 122 & $38.15(8.94)$ & & & \\
Duration of SM Usage & 3-4 Years & 106 & $41.41(8.01)$ & -2.88 & .004 & 0.38 \\
& & & & &
\end{tabular}

Note: $\mathrm{M}=\mathrm{Mean}, \mathrm{SD}=$ Standard Deviation, $\mathrm{FB}=$ Facebook

\section{DISCUSSION}

Study findings declare that Facebook is the SM type used by most of the participants, Whatsapp stood second in this category. Majority of the students presently are victims of using SM whether urban or rural and whether males or females (Kausar \& Awan, 2019). According to a recent report, $71 \%$ of teenage SM users access more than one SM and $24 \%$ of adolescents are "almost constantly" online due to the widespread use and popularity of smartphones (Lenhart et al., 2015). This study confirms that SM usage around the globe is an important issue to consider.

University students in Pakistan are under increased pressure due to higher academic standards in other countries, and it has become more important than ever for educators to encourage graduation and further education (Kausar \& Awan, 2019). Further Olowu and Seri 2012 reported a prevalence rate of $2.8 \%$ of addicted SM use among college students, while Jafarkarimi and Sim 2016 reported a prevalence rate of $47 \%$ being addicted to Facebook among a sample of college students.

The current generation of Pakistani youth might be suffering from Behavioral Addiction to SM use (Mazhar et al., 2020). Being a university or high school student does not make any difference on the level of social media addiction. However, significant differences were found regarding gender, duration of use, department at the university, and type of high school (Simsek et al., 2019). So, the usage of SM contributing its role in SMA in youth.

\section{CONCLUSION}

Current study aims to assess SMA level difference across age, Facebook usage or not, and duration of SM usage among late adolescence. To assess the objective of the study sample was collected from different academic institutions of Faisalabad by using convenience sampling. Data analysis in SPSS indicates that male gender is more addicted to SM. It also explains that as much as duration of SM usage increase SMA also increase.

\section{REFERENCES}

[1] Prajapati, P., Paul, S., Mehera, S., Malhotra, V., Sidhu, T. K., \& Verma, K. C. (2020). Social media, purpose, and use of it: A community-based cross-sectional study in a rural area of a developing nation (India). International Journal of Medical Science and Public Health, 9(5). https://doi.org/10.5455/ijmsph.2020.05073202001062020

[2] Demographics of social media users and adoption in the United States. (2019, June 12). Pew Research Center: Internet, Science \& Tech. https://www.pewresearch.org/internet/fact-sheet/social-media/

[3] Social media demographics to inform your brand's strategy in 2020. (2020, May 5). Sprout Social. https://sproutsocial.com/insights/new-social-media-demographics/\#IG-demos

[4] WhatsApp revenue and usage statistics (2020). (2020, June 23). Business of Apps. https://www.businessofapps.com/data/whatsapp-statistics/\#1

[5] Al-Menayes, J. J. (2015). Dimensions of social media addiction among university students in Kuwait. Psychology and Behavioral Sciences, 4(1), 23-28. https://doi.org/10.11648/j.pbs.20150401.14 
[6] Kauser, S., \& Awan, A. G. (2019). Impact of using social media on academic performance of students at graduate level: Evidence from Pakistan. Global Journal of Management, Social Sciences and Humanities, 5(1). https://www.academia.edu/38357352/IMPACT_OF_USING_SOCIAL_MEDIA_ON_ACADEMIC_PERFOR MANCE_OF_STUDENTS_AT_GRADUATE_LEVEL_EVIDENCE_FROM_PAKISTAN

[7] Lenhart, A., Duggan, M., Perrin, A., Stepler, R., Rainie, L., \& Parker, K. (2015). Smartphones facilitate shifts in communication landscape for teens. Teens, social media \& technology overview.

[8] Olowu, A. O., \& Seri, F. O. (2012). A study of social network addiction among youths in Nigeria. Journal of Social Science and Policy Review, 4(1), 63-71.

[9] Jafarkarimi, H., Sim, A. T. H., Saadatdoost, R., \& Hee, J. M. (2016). Facebook addiction among Malaysian students. International Journal of Information and Education Technology, 6(6), 465. https://doi.org/10.7763/ijiet.2016.v6.733

[10] Mazhar, N., Khan, T. B., Zafar, K., Warris, S. H., Nikhet, S., \& Tahir, A. (2020). A study of components of behavioral addiction to social media use in current generation of Pakistani youth. The Professional Medical Journal, 27(08), 1680-1685. https://doi.org/10.29309/tpmj/2020.27.08.4494

[11] Smek, A., Elciyar, K., \& Kizilhan, T. (2019). A Compaative Study on Social Media Addiction of High School and University Students. Contemporary educational technology, 10(2), 106-119. https://doi.org/10.30935/cet.554452

(C) 2020 Yaqoob et al.; Licensee ATSK Publishers.

This is an open access article licensed under the terms of the Creative Commons Attribution Non-Commercial License (http://creativecommons.org/licenses/by-nc/3.0/) which permits unrestricted, noncommercial use, distribution and reproduction in any medium, provided the work is properly cited. 